\title{
Espectro de gotas de pulverização e controle de doenças em duas cultivares de trigo
}

\author{
Spectrum spray droplets and control of diseases in two wheat cultivars
}

\author{
Caroline Almeida Gulart ${ }^{\mathrm{I}^{*}}$ Mônica Debortoli ${ }^{\mathrm{II}}$ Marcelo Madalosso ${ }^{\mathrm{II}}$ Ricardo Balardin ${ }^{\mathrm{I}}$ \\ Paulo Sergio dos Santos ${ }^{\mathrm{II}}$ Gerson Dalla Corte ${ }^{\mathrm{I}}$ Giuvan Lenz $^{\mathrm{I}}$ \\ Leandro Nascimento Marques ${ }^{\mathrm{I}}$
}

\section{RESUMO}

O objetivo do trabalho foi determinar a influência do número de gotas na penetração dos fungicidas e na sua eficácia de controle em diferentes momentos de aplicação. O delineamento experimental utilizado foi de Blocos ao acaso em parcelas subsubdivididas em quatro repetições. Os tratamentos foram constituídos por duas cultivares de trigo, 'Fundacep Cristalino' e 'Fundacep Nova Era'; três pontas de pulverização: XR 11002, TJ 6011002 e TX 8002 e o tratamento controle com e sem fungicida. Foi avaliada a densidade de gotas por centímetro quadrado, diâmetro mediano volumétrico (DMV), severidade das doenças, peso hectolitro e produtividade da cultura. $O$ espectro de gotas gerado pela ponta de pulverização XR 11002, nas condições do presente trabalho, apresentaram os melhores resultados em termos de deposição de gotas, controle das doenças e produtividade nas duas cultivares de trigo. $O$ controle das manchas foliares $e$ ferrugem -da- folha do trigo proporciona proteção do potencial produtivo da cultura, variando em função da suscetibilidade de cultivares e da cobertura e penetração de fungicidas.

Palavras-chave: Tecnologia de aplicação, penetração de gotas, manchas foliares, Puccinia graminis tritici, Triticum aestivum, controle de doenças.

\section{ABSTRACT}

The objective of this study was to determine the influence of the number of drops in the penetration of fungicides and their effectiveness in control at different times of application. The experimental design was randomized blocks in split split plots, totalizing 20 treatments in four replications, consisting of two wheat cultivars ('Fundacep Cristalino' and 'Fundacep Nova Era'); three spray nozzles (XR 11002, TJ 60-11002 and TX 8002), and control with and without fungicide. Was evaluated the density of droplets per square centimeter, volume median diameter (VMD), severity of disease, test weight and yield. The spectrum of droplets generated by the spray tip XR 11002 under the conditions of this study show the best results in terms of droplet deposition, disease control and yield in both wheat cultivars. The control of leaf spot and leaf rust of wheat provides protection of crop yield potential, varying depending on the susceptibility of cultivars and fungicides coverage and penetration.

Key words: Application technology, penetration drops, leaf spots, Puccinia graminis tritici, Triticum aestivum, disease control.

\section{INTRODUÇÃO}

A cultura do trigo está entre as mais importantes no cenário agrícola brasileiro, especialmente na região sul do país, onde está concentrada a maior parte da produção. De acordo com ZYLBERSZTAJN et al. (2004), essa é a principal fonte energética na alimentação da população de muitos países e a segunda em produção de grãos, ficando atrás apenas da cultura do milho. Apesar de o Brasil apresentar condições de solo, clima, material genético e também tecnologia disponível para cultivar mais de 10 milhões de hectares do cereal, a produção atual de 5,8 milhões de toneladas não supriu a demanda interna, que ficou em torno de 13,1 milhões de toneladas (AGRIANUAL, 2003).

Vários são os fatores que interferem de forma negativa na produtividade dessa cultura, tais como fertilidade do solo, condição climática, ataque de insetos-praga, doenças, entre outras. Nos últimos

IDepartamento de Defesa Fitossanitária, Centro de Ciências Rurais (CCR), Universidade Federal de Santa Maria (UFSM), 97105-900, Santa Maria, RS, Brasil. E-mail:carolgulart@yahoo.com.br. *Autor para correspondência.

IInstituto Phytus, Santa Maria, RS, Brasil. 
anos, tem ocorrido um aumento significativo na intensidade de doenças na cultura, especialmente aquelas causadas por fungos. Contudo, poucas são as alternativas eficazes para o controle das doenças, tornando o controle químico a única alternativa viável para garantir o potencial produtivo da cultura no Brasil (PICININI et al., 1993).

A cultura é atacada por uma grande diversidade de patógenos, tais como os causadores de manchas foliares, o oídio, as ferrugens e também as que atacam as espigas, podendo, dessa forma, causar danos consideráveis sob condições climáticas que favorecem epidemias. Os danos causados pela ocorrência de doenças são bastante variáveis, principalmente porque são influenciados por fatores como condições ambientais (chuvas frequentes), suscetibilidade de cultivares, agressividade dos patógenos, época do início da infecção, entre outros ( MEHTA, 1978; HETZLER et al., 1991). O aumento da intensidade dessas doenças na lavoura está relacionado a fatores como plantio direto, uso de sementes infectadas e, principalmente, à monocultura (FERNANDES E PICININI, 1999; PRESTES et al., 2002). Entretanto, a ferrugem-da-folha do trigo (Puccinia triticina Eriks) está disseminada em todo mundo, sendo uma das doenças mais prejudiciais à cultura.

A eficácia do controle químico está diretamente relacionada com a tecnologia de aplicação, do momento e qualidade da pulverização (REIS \& CASA, 2007). Em função dessa característica, a adequação da ponta de pulverização nos diferentes estádios de desenvolvimento da cultura do trigo, bem como do momento da patogênese, irá possibilitar a maximização do residual e da efetividade dos produtos sobre o controle das doenças.

É possível que diferentes pontas de pulverização promovam diferenças na deposição dos fungicidas no dossel da planta e, consequentemente, na penetração do produto, interferindo na eficiência destes no controle de doenças.

Com base nas informações apresentadas, o objetivo do presente trabalho foi determinar o espectro de gotas de três pontas de pulverização para o controle de manchas foliares e da ferrugem da folha em duas cultivares de trigo.

\section{MATERIAL E MÉTODOS}

O ensaio foi conduzido a campo, na safra de trigo 2010, em área experimental do Instituto Phytus - Núcleo de Pesquisa, localizado no município de Itaara, Região Central do Rio grande do Sul, localizado em latitude $29^{\circ} 35^{\prime} 8^{\prime}$ 'S, longitude $53^{\circ} 48^{\prime} 28^{\prime \prime} \mathrm{O}$ e altitude de $444 \mathrm{~m}$.

A instalação do experimento foi realizada nos estádios iniciais da cultura, sendo os tratamentos demarcados com o auxílio de estacas identificadas com números (tratamentos) e letras (repetições). A semeadura foi realizada no dia 06/07/2010. O espaçamento entre linhas foi de $0,17 \mathrm{~m}$ e a densidade de 350 sementes $\mathrm{m}^{-2}$. Para o manejo da área, foi utilizado $240 \mathrm{~kg} \mathrm{ha}^{-1}$ da formulação 8-28-18 (N-P-K) na adubação de base. A aplicação de ureia foi realizada no estádio de perfilhamento (ZADOKS et al., 1974) nos dias $11 / 08 / 2010$ e 22/08/2010, utilizando $50 \mathrm{~kg} \mathrm{ha}^{-1}$. Para o controle de insetos, foi utilizado inseticida Metamidofós (300g de i.a ha ${ }^{-1}$ ), na dose de $800 \mathrm{ml} \mathrm{ha}^{-1}$. Para o controle de plantas daninhas, utilizou-se o herbicida Hussar (Iodosulfurom metílico), na dose de $100 \mathrm{~g} \mathrm{ha}^{-1}$ em pósemergência.

O delineamento experimental utilizado foi o de blocos ao acaso em parcelas subsubdivididas com quatro repetições, sendo a unidade experimental de $6,12 \mathrm{~m}^{2}$.

As parcelas principais foram representadas pelas duas cultivares de trigo, 'Fundacep Cristalino' e 'Fundacep Nova Era'; subparcelas com três pontas de pulverização, XR 11002 (230kPa), TJ 6011002 (480 $\mathrm{kPa})$ e TX $8002(500 \mathrm{kPa})$ e o tratamento controle com e sem fungicida (Piraclostrobina + Epoxiconazol, 66,5+25g.i.a. ha ${ }^{-1}$ ) nas subsubparcelas.

A aplicação dos tratamentos foi realizada com um pulverizador costal pressurizado a $\mathrm{CO}_{2}$, acoplado a uma barra com quatro pontas espaçadas em $50 \mathrm{~cm}$, aplicando um volume de calda de $150 \mathrm{~L}$ $\mathrm{ha}^{-1}$. A aplicação dos tratamentos foi realizada em condições adequadas e nos estádios fenológicos de emborrachamento e florescimento (ZADOKS et al., 1974), respectivamente. Para tal, foram dispostos dentro das parcelas suportes subdivididos em três níveis, nos quais foram colocados cartões hidrossenssíveis presos com um grampo metálico. Imediatamente após a passagem da barra de pulverização, os cartões foram coletados em três repetições, identificados e guardados em embalagem, abrigadas da luz e umidade para posterior análise. A partir da coleta, foram obtidas imagens digitais com o auxílio de um scanner (1200 dpi). Após esse procedimento, as imagens foram submetidas à análise através do software e- Sprinkle ${ }^{\circledR}$, para determinação de densidade de gotas (DG), diâmetro mediano volumétrico (DMV), nos dosséis médio e inferior.

Foi avaliada a severidade de manchas foliares causadas por Drechslera tritici-repentis e Bipolaris sorokiniana e também de ferrugem-da- 
folha, causada por Puccinia triticina. As notas de severidade foram baseadas na metodologia descrita por PETERSON et al. (1948) para severidade de ferrugem-da-folha e por JAMES (1971), para severidade de manchas foliares, sendo realizadas aos 7, 14, 21 e 28 dias após a segunda aplicação dos fungicidas, considerando a planta inteira, no caso de manchas, e as folhas bandeira e bandeira ${ }^{-1}$, no caso da ferrugem da folha.

Com base na severidade das doenças, foi calculada a Área Abaixo da Curva de Progresso das Doenças (AACPD). Esse modelo remove a desuniformidade de progresso das doenças em ambientes naturais, possibilitando uma interpretação da epidemia. A Área Abaixo da Curva de Progresso de Manchas Foliares (AACPMF) e Área Abaixo da Curva de Progresso de Ferrugem da Folha (AACPFF) foram usadas como descritoras das respectivas epidemias, com o objetivo de analisar e comparar os dados de severidade que descreveram a epidemia (CAMPBELL \& MADDEN, 1990).

A produtividade foi obtida através da colheita manual de $6,12 \mathrm{~m}^{2}$ de plantas da parcela experimental, cortadas e trilhadas com uma trilhadora estacionária. O volume total de grãos foi pesado e determinada sua umidade, sendo posteriormente corrigido para $13 \%$, a fim de viabilizar o cálculo da produtividade final. O Peso hectolitro foi determinado de acordo com regras de Análise de Sementes (BRASIL, 1992) e os resultados expressos em $\mathrm{kg} \mathrm{HL}^{-1}$.

Os resultados obtidos foram submetidos à análise de variância e a interação entre os fatores, assim como suas médias foram comparadas através do teste de Tukey $(\mathrm{P}<0,01$ e $\mathrm{P}<0,05)$, com a utilização do pacote estatístico Assistat ${ }^{\circledR}$, versão 7.5 beta (SILVA \& AZEVEDO, 2002).

\section{RESULTADOS E DISCUSSÃO}

A análise da variância das variáveis relacionadas com a deposição de gotas não mostrou interação entre os fatores avaliados, com exceção da variável número de gotas por centímetro quadrado, avaliado no terço médio na segunda aplicação de fungicidas. Para o restante das variáveis, apenas o fator pontas de pulverização foi significativo em ambas as aplicações (Tabela 1).

$\mathrm{Na}$ primeira aplicação de fungicidas realizada no estádio de emborrachamento da cultura, não houve diferença estatística entre o número de gotas depositadas no terço médio, entretanto, o diâmetro mediano volumétrico das gotas pulverizadas pela ponta XR 11002 foi estatisticamente superior. Normalmente, ocorre uma maior cobertura do terço médio com relação ao inferior, principalmente porque o terço médio sofre menor interferência das folhas de cima.

Porém, essa diferença se acentua com o avanço do ciclo da planta em função do chamado "efeito guarda-chuva" e, dessa forma, o terço inferior tende a receber um menor número de gotas. Segundo ZHU et al. (2002), à medida que as plantas crescem, ocorre uma maior concentração das gotas no topo do dossel, sendo essa deposição muitas vezes maior que a obtida nos terços inferior e médio.

Por outro lado, no terço inferior do dossel, a ponta XR 11002 foi a que proporcionou maior cobertura e penetração de gotas, seguido pela TX 8002, diferindo estatisticamente das demais. Diversos trabalhos envolvendo tecnologia de aplicação demonstram que, quanto menor o DMV das gotas pulverizadas, maior será a área de cobertura das superfícies- alvo, expressas pelo número de gotas por $\mathrm{cm}^{2}$ (BOLLER, 2007; COSTA, 2009; LENZ, 2010). Quando entre duas ou mais gotas ocorrer uma sobreposição maior que $50 \%$, o software utilizado para realizar a análise dos cartões hidrossensíveis interpreta como se estas fossem apenas uma gota de maior diâmetro, fato que pode explicar o comportamento aqui encontrado.

Na segunda aplicação realizada, as pontas XR11002 e TX 8002 foram as que proporcionaram maior NGC no terço médio, diferindo estatisticamente da ponta TJ 60 (Tabela 1). No terço inferior do dossel, a ponta XR 11002 e TX 8002 proporcionaram o maior número de gotas $\mathrm{cm}^{-2}$, depositando nas folhas uma quantidade suficiente para proteger o tecido foliar (Tabela 1). Para OZEKI \& KUNZ (1996), uma densidade entre 30 e 50 gotas $\mathrm{cm}^{-2}$ é suficiente para adequada eficiência dos fungicidas sistêmicos. $\mathrm{Na}$ grande maioria das culturas e também nos cereais de inverno, a parte inferior do dossel da planta mantém por mais tempo o molhamento foliar, favorecendo, dessa forma, o início da infecção da maioria dos patógenos.

Entretanto, também é nessa porção das plantas que a cobertura e penetração dos fungicidas são mais prejudicadas com o avançar do estádio fisiológico da planta, o que favorece o estabelecimento do patógeno e reduz a eficácia do controle químico.

A aplicação do fungicida Epoxiconazol + Piraclostrobina proporcionou redução significativa da área abaixo da curva de progresso das duas doenças estudadas (Tabelas 2 e 3). A Piraclostrobina é um fungicida do grupo químico das estrobilurinas com característica de controle preventivo, agindo 
Tabela 1 - Comparação de médias de variáveis relacionadas com a deposição para três pontas de pulverização, nos terços médio e inferior nas duas aplicações de fungicidas. Santa Maria, 2012.

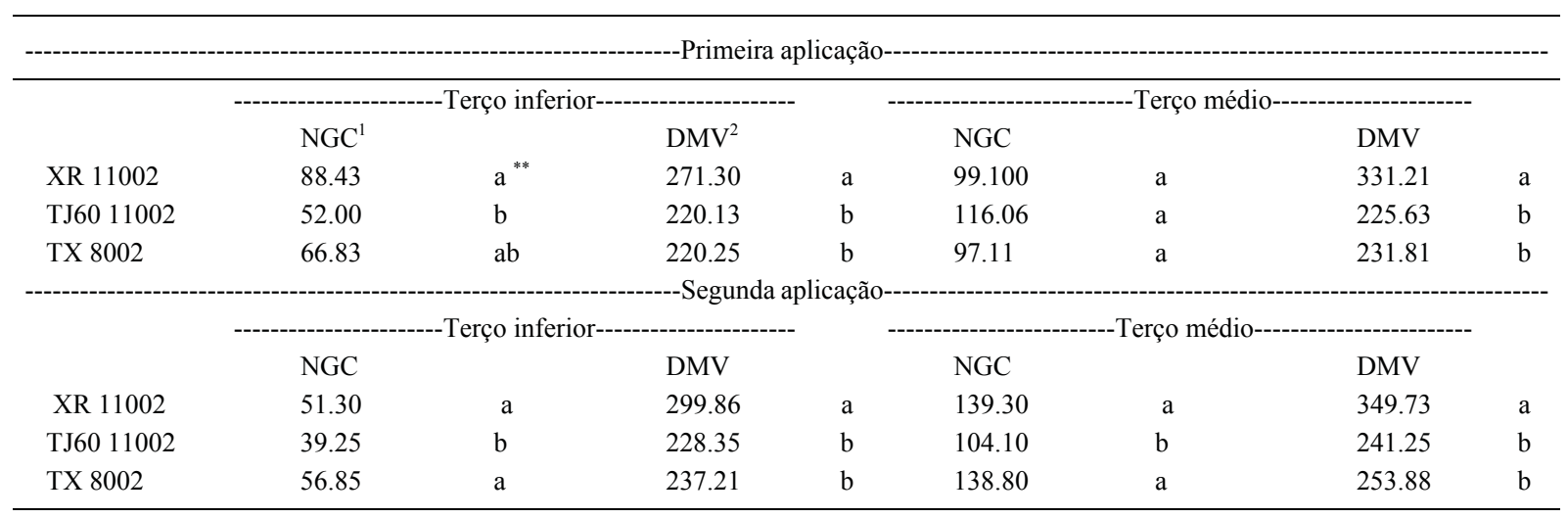

${ }^{1} \mathrm{NGC}$ : número de gotas por $\mathrm{cm}^{2} ;{ }^{2} \mathrm{DMV}$ : diâmetro mediano volumétrico $(\mu \mathrm{m})$; **Médias seguidas pela mesma letra minúscula nas colunas não diferem estatisticamente entre si pelo teste de Tukey em nível de $5 \%$ de probabilidade de erro.

na germinação dos esporos e oferecendo controle eficiente, tanto quando utilizado isolado quanto em combinação com fungicidas do grupo dos triazóis. $\mathrm{Na}$ verdade, há um sinergismo dos dois grupos químicos potencializando sua eficiência. As estrobilurinas apresentam maior estabilidade sob a ação do sol e "movimento de vapor" (fase gasosa do fungicida que permite a sua redistribuição nas plantas), garantindo às misturas uma eficiência superior, quando comparado aos fungicidas utilizados isoladamente (MACIEL \& CHAVES, 2008).

No caso da ferrugem-da-folha, pelo fato de a cultivar 'Nova Era' ser suscetível a essa doença, houve uma quantidade significativamente superior de doença com todas três pontas utilizadas com relação à cultivar 'Cristalino' (Tabela 2). Em função da pouca suscetibilidade da cultivar Cristalino às doenças, não houve diferença significativa entre as pontas de pulverização, entretanto, na cultivar 'Nova Era', a ponta XR 11002 foi a que proporcionou menor AACPF, fato diretamente relacionado com a maior cobertura proporcionada por essa ponta de pulverização nas duas aplicações de fungicida realizadas, que garantiram maior proteção do tecido foliar frente aos patógenos, diminuindo a quantidade de doença.

O mesmo comportamento foi observado com relação às manchas foliares, visto que, apesar de a cultivar 'Cristalino' ter apresentado uma quantidade menor de manchas foliares, não houve diferença entre as pontas utilizadas (Tabela 3). Porém, na cultivar 'Nova Era', ocorreu uma quantidade significativamente superior de doença, sendo que, novamente, a ponta XR 11002 proporcionou a menor quantidade de doença. Quando analisada a interação com e sem fungicida no estudo, essa ponta

Tabela 2 - Interações significativas com a Área Abaixo da Curva de Progresso da Ferrugem-da-folha (AACPF) após a aplicação de fungicida com diferentes pontas de pulverização em duas cultivares de trigo. Santa Maria, 2012.

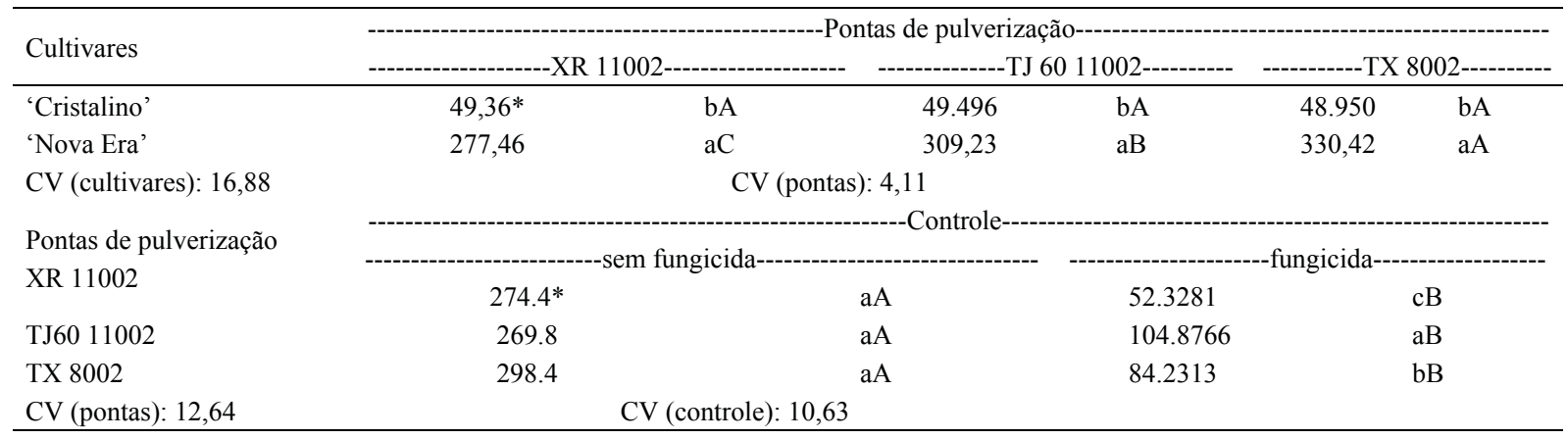

${ }^{*}$ Médias seguidas de letras iguais, maiúsculas na linha e minúsculas na coluna, não diferem pelo teste de Tukey, a 5\% de probabilidade.

Ciência Rural, v.43, n.10, out, 2013. 
Tabela 3 - Interações significativas com a Área Abaixo da Curva de Progresso de Manchas foliares após a aplicação de fungicida com diferentes pontas de pulverização em duas cultivares de trigo. Santa Maria, 2012.

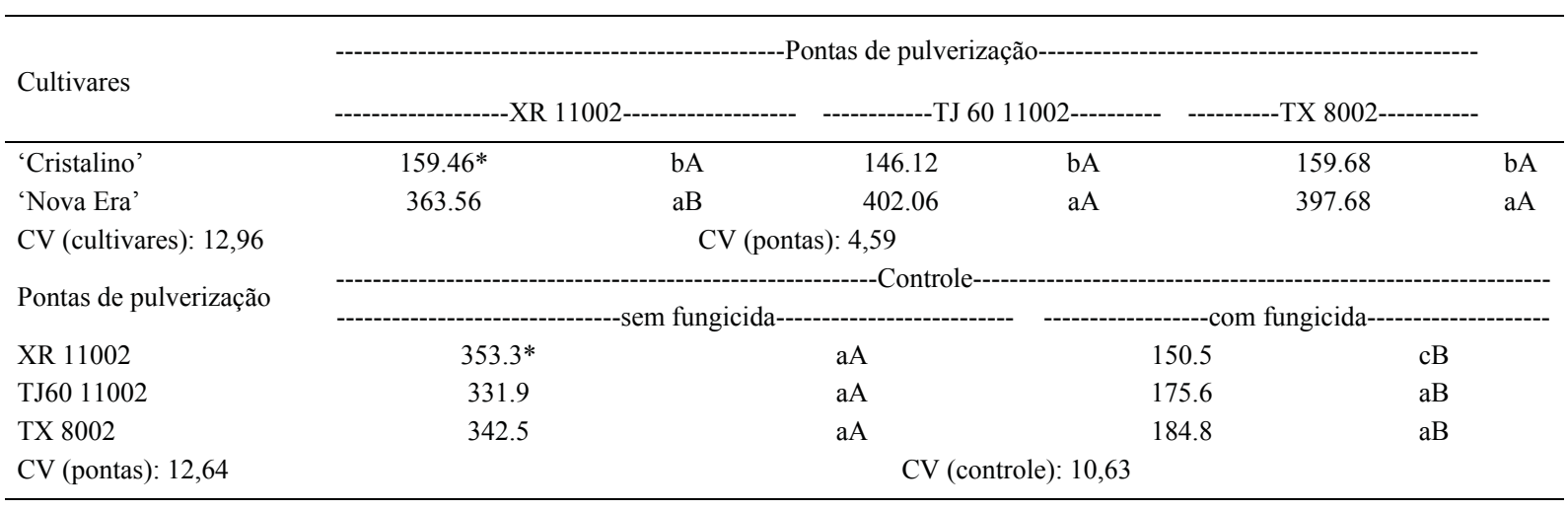

*Médias seguidas de letras iguais, maiúsculas na linha e minúsculas na coluna, não diferem pelo teste de Tukey, a 5\% de probabilidade.

de pulverização se destacou das demais tanto na penetração e cobertura de gotas (Tabela 1), quanto na apresentação das menores áreas abaixo da curva de progresso para as duas doenças (Tabelas 2 e 3 ). A distribuição vertical do seu jato na arquitetura ereta das folhas de trigo pode favorecer diretamente a maior penetração e cobertura de gotas, refletindo no controle eficaz, ao passo que as pontas TJ60 11002 e TX 8002 apresentam distribuição oblíqua dos seus jatos, encontrando resultados melhores em culturas palmadas (resultados não apresentados).

Os diferentes efeitos de controle das duas doenças refletiram diretamente no peso hectolitro ( $\mathrm{PH})$ e na produtividade das duas cultivares de trigo (Tabelas 4 e 5). Observou-se resposta positiva com relação ao PH pela utilização de diferentes pontas, no entanto, essa resposta não acompanhou a mesma tendência dos demais parâmetros com relação ao espectro gerado pelas pontas de pulverização. $\mathrm{Na}$ cultivar 'Cristalino', a ponta XR 11002 proporcionou maior peso hectolitro do que a ponta TJ 6011002 , não diferindo estatisticamente da ponta TX 8002. Já para a cultivar 'Nova Era', o maior valor de $\mathrm{PH}$ foi encontrado com a utilização da ponta TJ 6011002.

Outro comportamento que merece atenção é o fato de a cultivar 'Nova Era' ter apresentado um valor de $\mathrm{PH}$ superior à cultivar 'Cristalino' . Possivelmente, pelo fato da cultivar 'Nova Era' ser mais suscetível às doenças, especialmente à ferrugem, era esperado que apresentasse um valor de PH inferior, principalmente em função de ter manifestado uma quantidade de doença acumulada (AACPD) maior que a cultivar 'Cristalino'. De acordo com GONDIM et al. (2009), em situações de estresse e danos foliares, é comum a ocorrência de alterações na redistribuição de fotoassimilados e, dessa forma, ocorre a alteração da relação fontedreno. Talvez essa seja uma explicação para os valores

Tabela 4 - Peso hectolitro (PH) de duas cultivares de trigo após a aplicação de fungicida com três pontas de pulverização. Santa Maria, 2012.

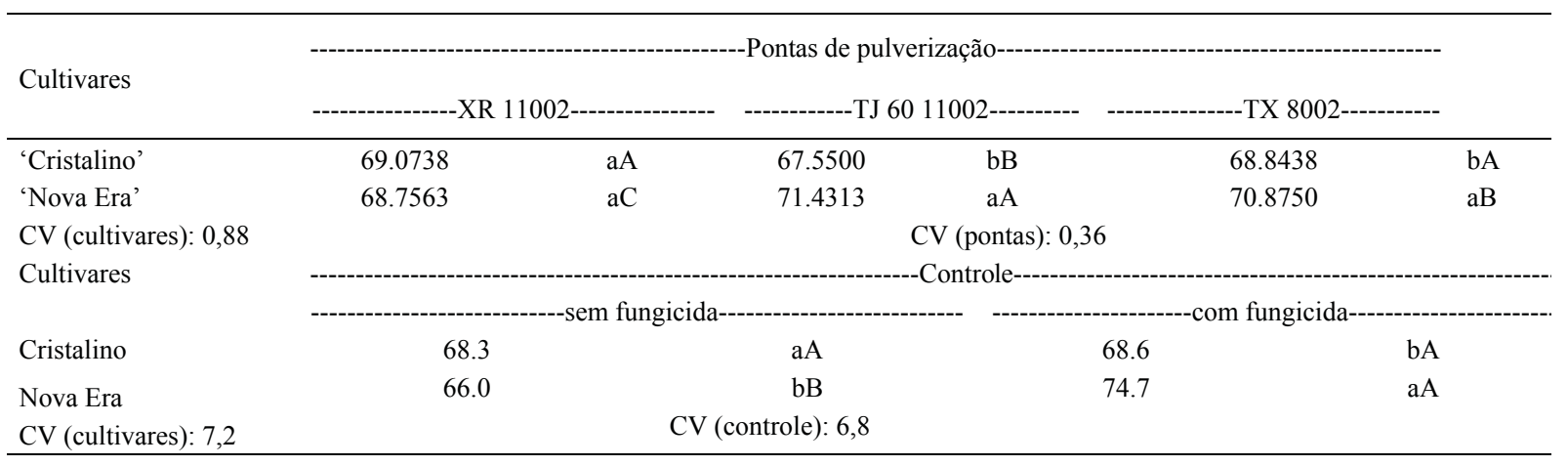

*Médias seguidas de letras iguais, maiúsculas na linha e minúsculas na coluna, não diferem pelo teste de Tukey, a 5\% de probabilidade.

Ciência Rural, v.43, n.10, out, 2013. 
Tabela 5 - Produtividade de trigo $\left(\mathrm{kg} \mathrm{ha}^{-1}\right)$ de duas cultivares de trigo após a aplicação de fungicida com três pontas de pulverização. Santa Maria, 2012

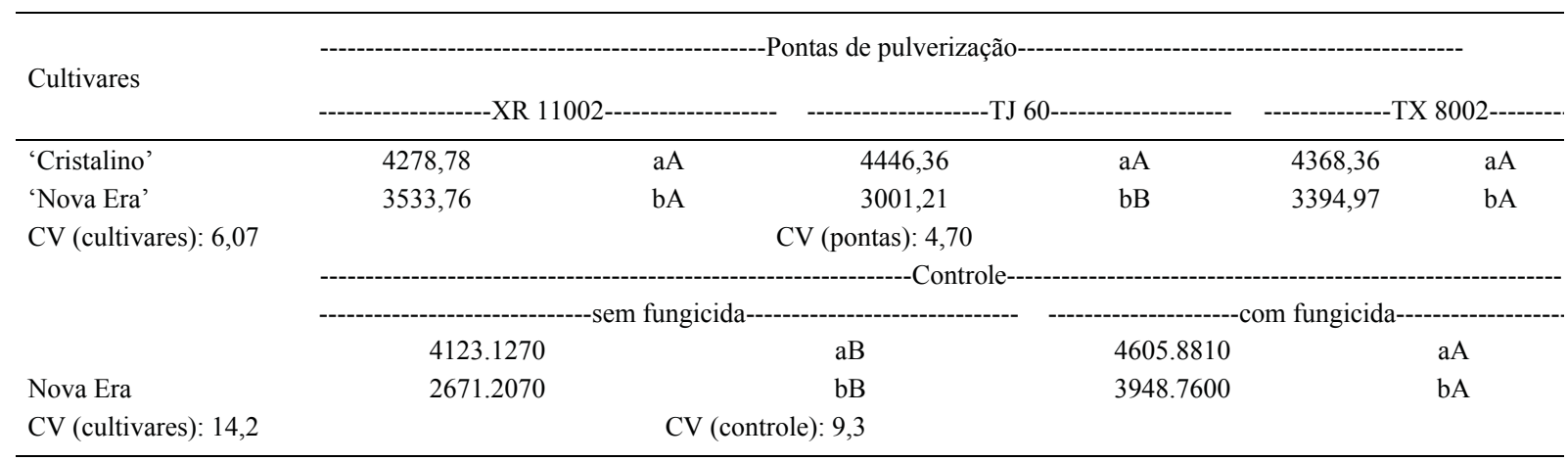

*Médias seguidas de letras iguais, maiúsculas na linha e minúsculas na coluna, não diferem pelo teste de Tukey, a 5\% de probabilidade.

de $\mathrm{PH}$ encontrados para as cultivares em estudo. $\mathrm{O}$ autor comenta que estudos mais aprofundados dessas relações são necessários para o conhecimento do funcionamento da partição de assimilados na planta em situações como a ocorrência de doenças.

Incrementos no rendimento de grãos de trigo foram obtidos com a aplicação do fungicida Epoxiconazol + piraclostrobina utilizando uma ponta XR 11001 (Tabela 5). Esse fato pode sugerir que pontas que produzem jato plano são mais eficientes para proporcionar penetração de gotas no dossel de plantas de trigo. Houve diferença significativa com relação à produtividade pela utilização das diferentes pontas de pulverização. Na cultivar 'Cristalino', por ter apresentado menor pressão de doenças, não houve diferença estatística entre as pontas. Já para a cultivar 'Nova Era', houve diferença significativa entre as pontas, sendo que as pontas XR 11002 e TX 8002 apresentaram rendimentos significativamente superiores. Porém, esse fator não pode ser considerado de forma isolada dentro do controle de doenças na cultura do trigo.

\section{CONCLUSÃO}

O espectro de gotas gerado pela ponta de pulverização XR 11002, nas condições do presente trabalho, apresentam os melhores resultados em termos de deposição de gotas, controle das doenças e produtividade nas duas cultivares de trigo.

$\mathrm{O}$ controle das manchas foliares e ferrugem-da-folha do trigo pode proporcionar proteção do potencial produtivo e qualidade de grãos da cultura, em função da suscetibilidade de cultivares e da cobertura e penetração de fungicidas.

\section{REFERÊNCIAS}

AGRIANUAL. Anuário Estatístico da Agricultura Brasileira. São Paulo: FNP Consultoria \& Comércio, 2003. 536p.

BOLLER, W. Resposta da tecnologia de aplicação de defensivos em relação à concepção atmosférica visando o controle de doenças de plantas. Summa Phytopathologica, v.33, supl, p.113-116, 2007.

BRASIL. Ministério da Agricultura e Reforma Agrária. Regras para análise de sementes. Brasília, 1992. 365p.

CAMPBELL, C.L.; MADDEN, L.V. Introduction to plant disease epidemiology. New York: John Wiley \& Sons, 1990. 532 p.

COSTA, D.I. Eficiência e qualidade das aplicações de fungicidas, por vias terrestre e aérea, no controle de doenças foliares e no rendimento de grãos de soja e milho. 2009. $144 \mathrm{f}$. Tese (Doutorado em Agronomia) - Universidade de Passo Fundo, Passo Fundo, RS.

FERNANDES, J.M.C.; PICININI, E.C. Sistema de suporte à tomada de decisão para otimização do uso de fungicidas na cultura do trigo. Fitopatologia Brasileira, v.24, n.1, p.9-17, 1999.

FIALLOS, F.R.G. et al. Eficiência de fungicidas no controle de doenças foliares na cultura do trigo, em resposta à aplicação com diferentes pontas de pulverização. ScientiaAgropecuaria, v.2,p.229-237,2011.Disponível em : <http://revistas.unitru.edu. pe/index.php/scientiaagrop/article/view/53/68>. Acesso em : 15 de out.2012.

GONDIM, A.R.O. et al. Qualidade de melão "Torreon" cultivado com diferentes coberturas de solo e lâminas de irrigação. Ceres, v.56, n.3, p.326-330, 2009. Disponível em: <http://www.ceres. ufv.br/ceres/revistas/V56N003P53109.pdf >. Acesso em :15 de out.2012.

HETZLER, J. et al. Interaction between Cochliobolus sativus and wheat cultivars. In: SAUNDERS, D.A. (Ed.). On wheat for nontraditional warmer areas. Cimmyt, Mexico: Proc Int Conf, 1991. p.146-164.

JAMES, W.C. An illustrated series of assessment keys for plant diseases, their preparation and usage. Canadian Plant Disease 
Survey, v.51, n.2, p.39-65, 1971. Disponível em: <http://phytopath. ca/download/cpds-archive/vol51/CPDS Vol 51 No 2 (3965)1971.pdf>. Acesso em : 05 de abr.2012.

LENZ, G. Efeito do espectro de gotas e idade de trifólios sobre a taxa de absorção de fungicidas em soja. 2010.73 p. Dissertação de Mestrado em Engenharia agrícola - Universidade Federal de Santa Maria. Santa Maria, RS.

MEHTA, Y.R. Doenças do trigo e seu controle. São Paulo: Agronômica Ceres/Summa Phytopathologica, 1978. 190p. (Ceres, 20).

MACIEL, J.L.N.; CHAVES, M.S. Desempenho do princípio ativo tebuconazole no controle da ferrugem da folha do trigo. In: PAINEL TÉCNICO: FUNGICIDAS TRIAZÓIS NO CONTROLE DA FERRUGEM DA FOLHA DO TRIGO. Passo Fundo: Embrapa Trigo, 2008. 3 p.

OZEKI, Y.; KUNZ, R.P. Tecnologia de aplicação aérea: aspectos práticos. In: CURSO E ATUALIZAÇÃO: TECNOLOGIA E SEGURANÇA NA APLICAÇÃO DE PRODUTOS FITOSSANITÁRIOS, 1996, Santa Maria, RS. Anais... Santa Maria: UFSM / Sociedade de Agronomia de Santa Maria, 1996. p.65-78.

PETERSON R.F et al. A diagrammatic scale for rust intensity on leaves and stems of cereals. Canadian Journal of Research, v.26, p.496-500, 1948. Disponível em: <http://www.nrcresearchpress. com/doi/pdf/10.1139/cjr48c-033>. Acesso em : 03 de jan.2013. DOI: $10.1139 /$ cjr48c-033

PICININI, E.C. et al. Effect of propiconazole spraiyng on yields of wheat and barley in southern Brazil during 1981 to 1992. In
INTERNATIONAL CONGRESS OF PLANT PATHOLOGY, 6. Montreal, 1993. (ABSTRACT).

PRESTES, A.M. et al. Práticas culturais e incidência de manchas foliares em trigo. Pesquisa agropecuária Brasileira, v.37, n.6, p.791-797, 2002. Disponível em: <http://seer.sct.embrapa. br/index.php/pab/article/view/6404/3461>. Acesso em: 05 de jan.2013.DOI: 10.1590/S0100-204X2002000600008.

REIS, E.M.; CASA, R.T. Doenças dos cereais de inverno: diagnose, epidemiologia e controle. 2.ed. Rev. Atual. Lages: GraPHel, 2007. 176p.

SILVA, F. de A.S. e; AZEVEDO, C.A.V. de. Versão do programa computacional Assistat para o sistema operacional Windows. Revista Brasileira de Produtos Agroindustriais, v.4, p.71-78, 2002. Disponível em: <http://www.deag.ufcg.edu.br/rbpa/rev41/ Art410.pdf $>$. Acesso em : 05 de jan.2013.

ZADOKS, J.C.et al. A decimal code for the growth stages of cereals. Weed Research, v.14, n.6, p.415-421, 1974. Diponível em: $<$ http://onlinelibrary.wiley.com/doi/10.1111/j.1365-3180.1974. tb01084.x/abstract>. Acesso em : 05 de jan.2013. DOI: 10.1111/ j.1365-3180.1974.tb01084.x.

ZHU, H. et al. Influence of plant structure, orifice size, and nozzle inclination on spray penetration into peanut canopy. Transactions of the ASAE, v.45, p.1295-1301, 2002. Disponível em: <http:// naldc.nal.usda.gov/download/31702/PDF $>$. Acesso em: $05 \mathrm{de}$ jan.2013. DOI: 10.1016/j.biosystemseng.2003.11.012.

ZYLBERSZTAJN, D. et al. Estratégias para o trigo no Brasil. São Paulo: Atlas, 2004. 224 p. 